ARTIGO

Recebido em: 12/01/2017

Aceito em: $18 / 06 / 2017$

\title{
Reflexões a partir da análise bibliométrica sobre tipos documentais, fluxos informacionais e avaliação de documentos
}

\author{
Reflections from the bibliometric analysis about documents types, \\ information flows and documents evaluation
}

\author{
Natália Marinho do NASCIMENT0 (natalianascimento_@hotmail.com)* \\ Marta Lígia Pomim VALENTIM (valentim@valentim.pro.br)* \\ María Manuela Moro CABERO (moroca@usal.es)** \\ * Doutoranda em Ciência da Informação - UNESP. \\ ** Professora do Departamento de Ciência da Informação - UNESP. \\ ** Professora do Departamento de Biblioteconomia e Documentação - Universidad de Salamanca / \\ Espanha.
}

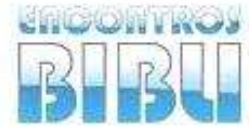

v. 22 , n. 50,2017 p. $59-75$

ISSN 1518-2924

\begin{abstract}
Resumo
Investigar elementos inter-relacionados que possam trazer vantagens para as organizações é essencial, principalmente, diante das novas demandas da gestão documental nesses ambientes. Analisa-se as citações em artigos de periódicos da área de Ciência da Informação, a partir das seguintes palavras-chave: tipos documentais, fluxos informacionais e avaliação de documentos, a fim de observar quais pesquisadores têm desenvolvido investigações sobre estas temáticas, buscando evidenciar se os textos apresentam algum tipo de relação entre as três temáticas supracitadas. No que tange aos procedimentos metodológicos, a pesquisa é do tipo descritiva-exploratória, de natureza qualiquantitativa. Nessa perspectiva, aplicou-se a análise bibliométrica, mais especificamente a análise de citação de 28 (vinte e oito) artigos selecionados, contemplando 489 (quatrocentas e oitenta e nove) citações. Observou-se que apenas 73 (setenta e três) pesquisadores investigam as temáticas supracitadas e, destes, apenas 4 (quatro) estabelecem algum tipo de relação entre elas. Evidencia-se a importância de estudos que investiguem e reflitam sobre essa inter-relação e o impacto desta para as organizações empresariais.
\end{abstract}

Palavras-Chave: Tipos documentais; Fluxos informacionais; Avaliação de documentos; Gestão Documental.

\begin{abstract}
Investigating interrelated elements that can bring advantages to organizations is essential, especially, given the new demands of records management in these environments. The citations are analyzed in articles from periodicals of the Information Science area, from the following keywords: documentary types, information flows and appraisal, to observe which researchers have developed investigations about these themes, seeking to evidence if the texts present relationship between the three themes mentioned above. As far as methodological procedures are concerned, the research is descriptive-exploratory, of a qualitative and quantitative nature. From this perspective, the bibliometric analysis was applied, more specifically the citation analysis of 28 (twenty-eight) selected articles, contemplating 489 (four hundred and eighty-nine) citations. It was observed that only 73 (seventy-three) researchers investigate the thematic mentioned above, of which only four (4) establish relationship between them. Highlights the importance of studies to investigate and reflect on this interrelationship and impact of this for business organizations.
\end{abstract}

Keywords: Documentary types; Information flows; Appraisal; Records management.

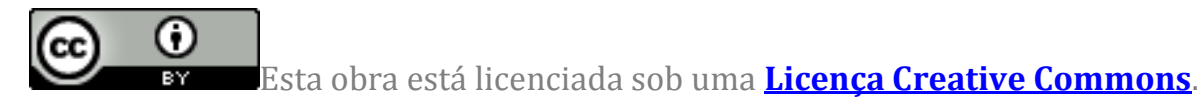




\section{INTRODUÇÃo}

Refletir sobre a inter-relação entre tipos documentais, fluxos informacionais e avaliação de documentos é fundamental para as áreas de Arquivologia e Ciência da Informação, uma vez que propicia observar de que maneira a gestão documental pode contribuir para a geração de diferenciais competitivos e, assim, gerar vantagem competitiva organizacional. Para tanto, analisou-se a literatura da área de Ciência da Informação e Arquivologia, mais especificamente a subárea 'Gestão de Documentos', a partir das seguintes palavras-chave: tipos documentais, fluxos informacionais e avaliação de documentos, a fim de observar quem são os autores que pesquisam sobre as referidas temáticas, se apresentam em seus textos algum tipo de relação entre as três temáticas, bem como refletir se há algum impacto para a geração de diferenciais significativos para a organização.

Destaca-se que são temas imprescindíveis para as áreas de Arquivologia e Ciência da Informação, bem como para as organizações empresariais, visto que se constituem em abordagens que evidenciam a importância de as empresas gerenciarem eficientemente a massa documental gerada em seu ambiente, abrangendo desde a produção, a tramitação até a destinação final: a eliminação ou guarda permanente. Considerando que nos entornos tecnológicos atuais, existe grande vulnerabilidade e fragilidade no que tange aos documentos eletrônicos, acredita-se que há uma necessidade de assegurar a autenticidade, integridade, confiabilidade e disponibilidade dos documentos. Além disso, o conhecimento sobre os documentos ocorre mediante o conhecimento dos contextos produtivos. Dessa maneira, a 'Avaliação' (Appraisal) está presente na norma ISO 15489-1:2016 revisada, em que dispõe no sétimo parágrafo sobre a necessidade de se compreender as atividades de negócio, mais especificamente no item 7.3 "Understanding business" para determinar o modelo de gerenciamento de documentos.

As organizações se constituem em ambientes complexos devido à vasta quantidade de documentos e informações que nem sempre são gerenciados e valorizados como insumo ou diferencial competitivo. Em trabalhos anteriores, foi possível evidenciar que as organizações falham no que tange a utilização de informações orgânicas para subsidiar o processo decisório, para garantir a governança, alcançar o cumprimento das leis e regimentos, bem como para obter a certificação de qualidade. Em geral, os documentos - e seus tipos documentais (em distintos suportes) - ainda não são identificados e controlados desde a sua produção, fator que resulta na impossibilidade de realizar o mapeamento de fluxos documentais e informacionais, consequentemente não apoiando os processos decisórios nem os processos vinculados para garantir a confiança, transparência e conferir a responsabilidade social da maneira que poderia/deveria ser.

A identificação de tipos documentais propõe alguns conhecimentos, estes são: dos conteúdos e formas existentes; o formato mais apropriado; a estrutura e tecnologia que devem ser usadas; como devem ser identificados e descritos; durante quanto tempo devem ser conservados; e que nível de segurança os documentos devem ter. Estas informações derivam-se do mapeamento dos fluxos informacionais/documentais e da avaliação de documentos. Nesse sentido, os conhecimentos supracitados devem ser considerados atividades necessárias para auxiliar as organizações no acesso e na recuperação de documentos, fornecendo continuidade digital no que tange ao ambiente tecnológico digital, bem como auxiliando o processo decisório em distintos tipos de atividades. Ressalta-se que as funções arquivísticas dependem dessas três atividades, por isso mesmo se torna essencial observar a literatura relacionada à gestão de documentos e Ciência da Informação, mais especificamente em relação a se os pesquisadores desta temática inter-relacionam os três enfoques, no intuito de obter uma gestão documental eficiente. 
Segundo o Dicionário de Terminologia Arquivística (1996, p.28), o conceito de documento se embasa na ideia de "unidade constituída pela informação e seu suporte", contudo, parte-se do pressuposto de que para ser informação deve haver a compreensão por parte de um receptor, ou seja, é fundamental considerar o conceito de documento de modo amplo, composto de "dados, matéria-prima da informação" (PÉRES-MONTORO, 2004) e seu suporte, cujo conteúdo tem potencial para ser informação, desde que seja compreendido por um receptor.

No que tange aos procedimentos metodológicos, a pesquisa é do tipo descritiva-exploratória, de natureza qualiquantitativa. Para tanto, aplicou-se a análise bibliométrica, mais especificamente a análise de citação em 28 (vinte e oito) artigos selecionados da Base de Dados Referencial de Artigos de Periódicos em Ciência da Informação (BRAPCI) (Apêndice A), a partir das seguintes palavraschave: tipos documentais, fluxos informacionais e avaliação de documentos, contemplando 489 (quatrocentas e oitenta e nove) citações.

\section{AMBIENTES ORGANIZACIONAIS}

A gestão de documentos ${ }^{1}$ pode contribuir efetivamente para a eficiência de ambientes organizacionais, por meio da aplicação de métodos e técnicas que possibilitem a gestão da informação ${ }^{2}$ e a gestão do conhecimento ${ }^{3}$, auxiliando os gestores a tomarem decisões que propiciem atingir os objetivos e as metas organizacionais, uma vez que são atividades que geram valor e garante o cumprimento de requisitos legislativos e normativos, bem como o atendimento às expectativas de clientes e interessados.

Evidencia-se por meio da dissertação de mestrado (NASCIMENTO, 2014) que, ainda não existe a efetiva atuação dos arquivistas em organizações empresariais. Ao observar as ofertas online do setor profissional no âmbito internacional, percebe-se que boa parte das demandas procedem de empresas que visam a gestão documental, ou seja, são inúmeros os desafios para esses profissionais, uma vez que se constata a necessidade de conquistar esse espaço de trabalho explorando as competências e as habilidades adquiridas durante a formação, visando colocá-las em prática, a fim de mostrar para esse nicho de mercado, quais as contribuições reais que podem proporcionar para esses ambientes, destacando que os principais riscos estão vinculados à continuidade digital.

Por outro lado, as organizações são compreendidas como um "[...] complexo sistema de decisões [...] todas as pessoas na organização, em todas as áreas de atividades e níveis hierárquicos e em todas as situações estão continuamente tomando decisões relacionadas ou não com o seu trabalho" afirma Chiavenato (2003, p.347). Nessa perspectiva, o processo decisório é composto por decisões e, consequentemente, essas serão à base de todas as ações e processos organizacionais. Desse modo, possibilitar que as informações orgânicas cheguem até os gestores no tempo certo e com a qualidade necessária, garante que as organizações gerem diferenciais competitivos. Em busca de se alcançar eficácia nas atividades organizacionais, as organizações estão interessadas em demonstrar outros requisitos que manifestem uma adequada gestão e governança, cujos requisitos consistem em melhorar a própria imagem e demonstrar transparência em relação a prestação de contas. Somente é possível alcançar essas metas sustentandose em bons canais de informação e de documentação e, para tanto, é essencial uma rigorosa base documental. Devido a tal fato, estudar esses ambientes complexos e analisar maneiras de maximizar os processos e ações direcionados aos tipos documentais, fluxos informacionais e avaliação de documentos, certamente contribui efetivamente para as empresas e para a própria sociedade. 


\title{
2.1 Tipologia Documental e Ambientes Organizacionais
}

A Tipologia Documental também é conhecida por muitos autores como Diplomática Contemporânea (RODRIGUES, 2008; BELLOTTO, 2002; DELMAS, 1996 , entre outros) e é caracterizada por estudar o documento enquanto pertencente de conjuntos orgânicos. Para Camargo e Bellotto (1996, p.74) é entendida como o "[...] estudo dos tipos documentais". 0 estudo dos tipos documentais é efetivado por meio da identificação de documentos, que para Heredia Herrera (2011) significa "[...] o processo de reconhecer uma entidade arquivística por seus atributos específicos" (HEREDIA HERRERA, 2011, p.123, tradução nossa). A autora o considera um processo de análise, ou seja, um processo intelectual. Sem ele, não é possível desenvolver outros processos chave da gestão documental, tais como a classificação, a descrição, a avaliação, bem como o acesso, a recuperação, a conservação e a difusão. A identificação é um processo fundamental, tendo em vista que:

Tipos documentais representam a união entre a função administrativa e o documento que a registra e que induza que ela se cumpra. Se a espécie documental é a configuração que assume o documento segundo sua finalidade, o tipo documental é a configuração que ela assume segundo a atividade que a gerou (BELLOTTO, 2014, p.347).

Nos ambientes organizacionais o arquivista deve considerar a identificação de documentos como uma ação essencial para o desenvolvimento de seus serviços, pois é para o cumprimento deste processo que ele estuda a produção documental, bem como define séries, subséries, grupos e subgrupos e que vai subsidiar toda a gestão documental. "Considerando-se essas definições, conclui-se que pelo tipo documental, coincidente com as séries, reconhecem-se as atividades e os desdobramentos operatórios das funções da entidade acumuladora" (BELLOTTO, 2014).

De acordo com Rodrigues (2008, p.202), os tipos documentais auxiliam as organizações,

\begin{abstract}
[...] no aprimoramento das tarefas realizadas pelos administradores envolvidos com os procedimentos de gestão documental, melhorando a tramitação, a produção e o controle do arquivamento de documentos junto aos órgãos produtores. Na medida em que fornecesse informações precisas sobre as características da ação administrativa e de seu produtor, registrados nos tipos documentais, as informações produzidas sobre as séries documentais se tornam a base para a realização das tarefas desenvolvidas pelo arquivista. A identificação é condição sine qua non para o desenvolvimento das funções arquivísticas da avaliação, classificação, descrição e também da produção documental (RODRIGUES, 2008, p.202-203).
\end{abstract}

Ressalta-se que a organização que não valoriza os documentos produzidos e não reconhece a importância da identificação desde a produção de documentos, para atingir os objetivos e metas e auxiliar os gestores na tomada de decisão, tende a não estar preparada para as mudanças que ocorrem no mercado, bem como não terão melhores condições para enfrentar as crises e os riscos.

Quando há o reconhecimento dos tipos documentais desde o momento em que são produzidos, se estabelece a possibilidade real de acesso e recuperação de diferentes informações que, por sua vez, são relevantes para a organização, porquanto os documentos configuram-se em uma espécie de espelho das mesmas. No caso dos documentos digitais, por exemplo, a tipologia documental não se restringirá apenas a recuperação do contexto mediante a análise da forma, ela estuda os elementos externos e internos dos documentos auxiliando no 
estabelecimento de metadados (E-ARQ BRASIL ${ }^{4}, \mathrm{MOREQ}^{5}, \mathrm{E}^{-\mathrm{PMG}^{6}}$ etc.) que, por sua vez, auxilia na preservação dos documentos em todo o seu ciclo vital.

Atualmente, a produção de documentos eletrônicos no ambiente de negócios influi diretamente na atuação dos gestores de documentos, abrangendo desde a criação para garantir seu controle até seu armazenamento ou eliminação. Os sistemas informáticos nos quais se produz o documento (assegurando que determinados critérios oriundos da gestão documental se cumpram) devem apoiarse em padrões que proporcionem controle, tanto no que tange à tipologia quanto em relação ao formato.

\subsection{Fluxos de Informações}

Os tipos documentais se constituem nos fluxos informacionais formais ou estruturados, ou seja, configura-se nas informações que estão materializadas em algum suporte, assim, não existe fluxo informacional formal sem tipos documentais, ou seja, um elemento sustenta o outro e estão totalmente inter-relacionados nos ambientes organizacionais. A gestão documental normalizada é considerada essencial para o desenho de um modelo de gestão, a análise dos contextos (externo e interno) da organização. É precisamente a análise interna, que enquadra o mapeamento dos fluxos informacionais, mediante a análise das funções, processos e atividades do negócio e estratégias que estão relacionadas ao organismo produtor. Tanto o modelo ISO 15489-1:2016, quanto a série de normas ISO 30300:2011 e, mais concretamente, a norma ISO 30301:2011 destacam a importância da análise dos contextos organizacionais. 0 quarto parágrafo desta última norma salienta a necessidade de se compreender esse contexto para conhecer os requisitos do negócio relacionados às questões legais ou sociais vinculados à gestão documental e, assim, definir o alcance do sistema de gestão documental. Precisamente, a estrutura do Sistema de Gestão de Documentos (SGD) (ISO 30301:201, p.8) se sustenta sobre o conhecimento do contexto organizacional. Destaca-se, entre outros aspectos constantes da referida norma, "[...] os sistemas de informação, os fluxos de informação e os processos de tomada de decisão (formais e informais)" (ISO 30301:2011, p.9, tradução nossa). 0 compartilhamento e a comunicação de dados e informação se constituem na dinâmica dos fluxos informacionais. Ressalta-se que estes são essenciais em qualquer ambiente organizacional. Além dos fluxos de informações existirem formalmente nesses ambientes, também se faz necessário trabalhá-los, ou seja, mapeá-los e gerenciá-los.

Para Castells (2001, p.501), os fluxos são compreendidos por "[...] sequências intencionais, repetitivas e programáveis de intercâmbio e interação entre posições fisicamente desarticuladas, mantidas por atores sociais nas estruturas econômica, política e simbólica da sociedade", ou seja, envolve todos os aspectos concernentes à própria dinâmica organizacional, uma vez que aborda a dinâmica da informação num determinado ambiente.

Segundo Valentim (2010, p.13):

Os fluxos de informação ou fluxos informacionais se constituem em elemento fundamental dos ambientes informacionais, de tal forma que não há ambiente informacional sem haver fluxos de informação e vice-versa. Os fluxos informacionais são reflexos naturais dos ambientes ao qual pertencem, tanto em relação ao conteúdo quanto em relação à forma.

Ademais, os fluxos informacionais são dinâmicos e envolvem distintas ações de envio e de recepção de documentos/informações havendo necessariamente um ponto de partida e um ponto de chegada. A produção de documentos alimenta os fluxos informacionais, uma vez que materializa em um suporte/mídia a função designada aos sujeitos organizacionais. 
A gestão documental integrada propicia que os documentos passem a ter os fluxos de informação mais bem gerenciados, revelando como ocorre o trâmite documental entre as mais diversas áreas de uma organização. Sendo assim, entendese que os fluxos documentais são oriundos da gestão documental que, consequentemente, é necessária para que haja os fluxos de informação. Trata-se de uma alimentação contínua, mas, se não é assegurada a veracidade e continuidade dos fluxos documentais de modo sustentável será impossível inter-relacionar a dinâmica complexa entre dado, documento/informação e conhecimento.

Não há uma diferença no que tange à importância, ao contrário, ambos funcionam em conjunto, ou seja, é necessário identificar os fluxos de informação para posteriormente identificar os fluxos de documentos. Nesse sentido, nos fluxos documentais os documentos percorrem um caminho para a efetivação de uma atividade e/ou tarefa, e existem as ferramentas específicas que auxiliam as organizações no gerenciamento deste tipo de fluxo.

"Subdividir os sistemas em subsistemas e estudá-los separadamente, de maneira a conhecer como flui a informação em cada um deles e entre cada subsistema e, posteriormente, o sistema geral com o ambiente" é o que Villardefrancos Álvarez (2002, p.12) considera essencial para o estudo dos fluxos informacionais em qualquer organização. Para tanto, é preciso considerar acerca dos fluxos informacionais três aspectos: "1) como flui a informação dentro de cada área; 2) como flui a informação entre os diferentes subsistemas da área; e 3) como flui a informação entre a área e o ambiente organizacional" (VILLARDEFRANCOS ÁLVARES, 2002). A delimitação dessas áreas é vital para determinar a fidedignidade dos fluxos de documentos e de informações, perceber os riscos existentes, elaborar a classificação funcional das áreas, funções, processos e atividades, delimitar o perfil na sua descrição mediante metadados e qualificar os documentos para sua avaliação e disposição.

Os fluxos informacionais não são resumidos a um processo constituído da interação entre o indivíduo e uma determinada estrutura, mas sim como fator primordial para a própria produção de conhecimento, isso significa que a construção de conhecimento em estruturas organizacionais é dependente dos fluxos informacionais.

Desse modo, os fluxos informacionais são relacionados a três fatores: a) aos indivíduos que necessitam de informação; b) a informação gerada por sujeitos organizacionais; c) a apropriação da informação entendida como uma modificação do estado cognitivo do indivíduo, ou seja, a efetivação do conhecimento. Nessa perspectiva, a significação deve ocorrer para que o indivíduo compreenda se as informações são relevantes ou não para satisfazer suas necessidades, e para que haja essa modificação do estado cognitivo do indivíduo, também ocorre outro processo de significação, visto que este processo ocorre a todo o momento para que ocorra a comunicação entre os indivíduos, e para que seja possível a construção de conhecimento. 0 processo de construção de conhecimento aqui entendido, só ocorre efetivamente quando de alguma maneira o sujeito consciente transmite o conhecimento tácito para algum meio a fim de comunicar-se. Esse processo supõe necessariamente a mediação do indivíduo com os documentos/informações, tanto para se comunicar quanto para contemplá-los como fator de evidência dos atos.

Além disso, existe uma divisão acerca dos fluxos informacionais que são os fluxos informacionais formais (estruturados) ou informais (não estruturados). Para Valentim (2010, p.18-19),

Os fluxos informacionais estruturados se caracterizam por sua visibilidade, se constituem no resultado das atividades e tarefas desenvolvidas de forma repetitiva [...] os fluxos informacionais não-estruturados se caracterizam, quase sempre, por sua 
invisibilidade, porquanto se constituem no resultado de vivências e experiências individuais e grupais dos sujeitos [...].

Os fluxos estruturados consistem em informações que de alguma maneira estão registradas em algum tipo de suporte, por outro lado os fluxos não estruturados se constituem em informações não registradas, mas nem por isso deixam de ser informação.

Os fluxos informais ou não estruturados fazem parte dos recursos não tangíveis que uma organização possui. No entanto, possuem grande relevância para a organização, e abrangem o conhecimento gerado no ambiente organizacional e, que muitas vezes, não foram percebidos e sistematizados. Este tipo de conhecimento quando sistematizado e trabalhado pode auxiliar a organização em distintos e significativos momentos.

Os fluxos formais ou estruturados são constituídos de informações, ou seja, fazem parte dos recursos tangíveis que a organização possui. Este fluxo "[...] referese à informação que perpassa formalmente as diferentes unidades de trabalho como diretorias, gerências, divisões, departamentos, setores, seções etc., por meio de memorandos, atas, relatórios, planilhas, e-mails etc." detalham Monteiro e Valentim (2008, p.55).

A relação entre tipos documentais e fluxos informacionais se dá no âmbito do fluxo informacional estruturado ou formal, pois os tipos documentais são as funções e atividades de uma organização materializadas em algum suporte, quando estes documentos (independente do suporte) são identificados no momento de estudo da produção documental há uma grande efetividade no que tange à recuperação destas informações, bem como sua preservação e acesso. Além disso, mapear os fluxos não estruturados é difícil, visto que as informações não são consolidadas em suportes/mídias, ou seja, há maior dificuldade em percebê-la e, assim, realizar as demais atividades que possam transformá-la em informação estruturada, visando sua disseminação.

Assim, os tipos documentais (informações orgânicas reconhecidas) constituem os fluxos informacionais formais dos ambientes organizacionais, isto é, o reconhecimento dos tipos documentais está estritamente relacionado com a identificação dos fluxos formais. Nessa perspectiva, acredita-se que é necessário identificar os tipos documentais, uma vez que eles se constituem na matéria prima dos fluxos formais, pois é a identificação desses elementos que possibilitará às organizações usarem informações de maneira estratégica, desenvolver inteligência organizacional, cujos objetivos é gerar inovação e diferenciais competitivos frente aos concorrentes.

\subsection{Avaliação de Documentos}

Cermeño Martorell e Rivas Palia (2010, p.59, tradução nossa) explicam que a avaliação tem uma forte relação com os demais processos arquivísticos, uma vez que “[...] a identificação das séries está totalmente relacionada à avaliação, pois o primeiro passo para avaliar qualquer série é tê-la identificada e definida". Dessa maneira, a avaliação é defendida por Hernández Olivera e Moro Cabero (2002, p.29, tradução nossa) como

[...] um processo intelectual com o qual se determina:

a) 0 fluxo documental e seu controle em atenção ao uso e valores dos documentos de uma organização;

b) Em função do estudo e análise dos prazos e valores dos prazos de vida documental e dos valores, aspectos relacionados com o suporte e a conservação dos documentos, assim como outros fatores relativos à eliminação total ou parcial dos documentos e; 
c) 0 conjunto de documentos que deve incorporar-se a um sistema de gestão eletrônica de documentos.

Segundo o Conselho Nacional de Arquivos (2001, p.42),

A avaliação constitui-se em atividade essencial do ciclo de vida documental arquivístico, na medida em que define quais documentos serão preservados para fins administrativos ou de pesquisa e em que momento poderão ser eliminados ou destinados aos arquivos intermediário e permanente, segundo o valor e o potencial de uso que apresentam para a administração que os gerou e para a sociedade.

Além disso, tem-se que os objetivos básicos da avaliação de documentos para Bernardes (1998, p.15) são: “[...] redução da massa documental; agilidade na recuperação dos documentos e das informações; eficiência administrativa; melhor conservação dos documentos de guarda permanente; racionalização da produção e do fluxo de documentos (trâmite); liberação de espaço físico; e incremento à pesquisa". A avaliação está estritamente relacionada com a análise do contexto de produção e se fundamenta sobre a série e, portanto, sobre os documentos que a compõe. Hernández Olivera e Moro Cabero (2002, p.62, tradução nossa) explicam que

[...] deve-se reunir informação sobre o contexto em que a documentação foi criada, dado que esta reflete os valores, tendências e funções da entidade responsável por sua produção. Em segundo lugar, informação sobre a própria documentação, sua origem, função, tramitação, conteúdos etc.

A avaliação nos ambientes eletrônicos alcança mais força e sua realização resulta imprescindível para assegurar adequadas estratégias de preservação.

Os documentos modernos são muito volumosos e mesmo com as tentativas atuais de diminuí-los em suporte papel, observa-se que isso está ainda longe de acontecer, de acordo com Schellenberg (2006, p.179), o crescimento em volume "[...] corresponde ao aumento da população, a partir de meados do século XVIII", com o aumento da população tornou-se necessária a expansão da atividade governamental bem como a privada, consequentemente resultando em um aumento na produção de papéis.

Para Schellenberg (2006, p.179), a “[...] redução na quantidade de tais documentos torna-se essencial [...] torna-se impossível prover espaço para armazená-los, bem como pessoal para cuidar dos mesmos. 0 custo da manutenção de tais papéis vai além das posses da mais rica nação", este autor destaca também os documentos de ordem pública, no entanto, isso ocorre em todos os âmbitos, inclusive nos ambientes organizacionais, principalmente porque precisam reduzir custos e aumentar a produtividade e, por isso, os arquivos não costumam ser priorizados nas organizações, entretanto, isso é algo que precisa ser mudado e as políticas de avaliação de documentos devem ser implementadas para ajudar a informar os gestores que ainda possuem essa opinião.

Atualmente, a avaliação é considerada um macroprocesso, mediante o que se avalia no contexto do negócio e dos processos para determinar o que é necessário para os documentos serem criados, capturados e geridos para uso e durante quanto tempo devem ser preservados (ISO 15489-1:2016, parágrafo 7.1). Este macroprocesso inclui a análise de risco dos documentos em cada processo.

Destaca-se que este processo é relevante, e para que seja desenvolvido nas organizações é necessário que todos se empenhem juntamente ao profissional arquivista, afinal é indispensável realizar um estudo detalhado acerca dos documentos em si, suas funções, a legislação vigente, entre outros aspectos. Além 
disso, normalmente são designados grupos denominados de Comissões Permanentes de Avaliação de Documentos (CPAD) responsáveis pelas decisões de avaliação dos documentos gerados.

É necessário ressaltar também a relação e a importância para os ambientes eletrônicos entre a identificação de documentos e a avaliação. A avaliação em ambientes digitais precisa da identificação, para poder definir estratégias de conservação neste âmbito, dado que essas confluem considerando a comunidade designada para que se conserve ou não os documentos e outros critérios de interesse como volume, custos, formatos, suportes, marco legal etc.

Entende-se que para haver efetividade nos processos organizacionais é preciso que a avaliação de documentos (estabelecimento de valor), a identificação de documentos (reconhecimento dos tipos documentais), bem como o mapeamento dos fluxos informacionais (e no caso deste trabalho o foco se volta ao fluxo informacional formal) caminhem em conjunto. Defende-se que se houver o bom funcionamento entre esses três elementos, certamente haverá a efetividade de distintos processos, em especial do processo decisório.

\section{PROCEDIMENTOS METODOLÓGICOS}

A pesquisa é do tipo descritiva-exploratória, de natureza qualiquantitativa, assim, aplicou-se a análise bibliométrica, mais especificamente a análise de citação. Este estudo possibilitou identificar quais são os pesquisadores das áreas de Arquivologia e de Ciência da Informação que investigam os fluxos informacionais, tipos documentais e avaliação de documentos de modo integrado.

Para a análise bibliométrica, selecionou-se a base de dados brasileira 'BRAPCI' para levantamento dos artigos, sendo considerado válido o intervalo dos últimos 15 (quinze) anos, ou seja, de 2000 a 2015. Os textos foram selecionados por meio das seguintes palavras-chave:

1. Fluxos Informacionais; Information Flows; Flujos de Información;

2. Tipos Documentais; Documentary Types; Tipos de Documentos;

3. Avaliação de Documentos; Appraisal; Valoración de Documentos.

As palavras-chave supracitadas foram analisadas nos seguintes campos: título, resumo e palavras-chave.

A partir da estratégia de busca, selecionou-se 28 (vinte e oito) artigos (Apêndice A), sendo 14 (quatorze) sobre 'fluxos informacionais'; 4 (quatro) sobre 'tipos documentais'; e 10 (dez) sobre 'avaliação de documentos'. Após a seleção dos referidos textos, analisou-se as referências utilizadas e o desdobramento das autorias múltiplas de modo que contemplasse o nome de todos os autores citados, posteriormente, realizou-se a triagem das citações e, por fim, foram colocadas em ordem alfabética de maneira a observar os autores com maior número de textos citados, o número total de citações consistiu em 489 (quatrocentos e oitenta e nove).

No que tange à primeira temática 'fluxos informacionais' identificou-se 284 pesquisadores citados, para um total de 295 referências, destacando-se que 261 $(91,9 \%)$ pesquisadores foram citados apenas uma vez; $12(4,22 \%)$ foram citados duas vezes; $8(2,82 \%)$ foram citados três vezes; $2(0,70 \%)$ foram citados quatro vezes; e apenas $1(0,35 \%)$ pesquisador foi citado seis vezes.

Em relação à temática 'tipos documentais' identificou-se 42 pesquisadores citados, para um total de 60 referências. Destaca-se que 33 (78,57\%) pesquisadores foram citados apenas uma vez; $5(11,90 \%)$ foram citados duas vezes; $2(4,76 \%)$ foram citados três vezes; 1 (2,38\%) foi citado quatro vezes; e 1 (2,38\%) foi citado sete vezes. 
Quanto à temática 'avaliação de documentos' identificou-se 163 pesquisadores citados, para um total de 248 referências, sendo que $120(73,62 \%)$ pesquisadores foram citados apenas uma vez; 27 (16,56\%) foram citados duas vezes; 7 (4,29\%) foram citados três vezes; 2 (1,22\%) foram citados quatro vezes; 2 $(1,22 \%)$ foram citados cinco vezes; $3(1,84 \%)$ foram citados seis vezes; $1(0,61 \%)$ foi citado em sete vezes; e $1(0,61 \%)$ foi citado dez vezes.

Diante da análise bibliométrica das citações dos 28 artigos, selecionou-se 73 autores que possuíam duas ou mais citações, no intuito de ressaltar sua representatividade. A partir disso, construiu-se um quadro (Quadro 1) contendo os autores mais produtivos das três temáticas centrais, isto é, os autores que discutem duas ou três temáticas anteriormente mencionadas, bem como se existe alguma inter-relação entre elas. Após a elaboração do Quadro 1, também se elaborou a rede de autores evidenciando os dados obtidos, construída a partir do uso do software 'UCINET' (Figura 1).

As etapas realizadas para a elaboração da rede por meio do software 'UCINET' foram: a) elaboração da matriz por meio dos dados expostos (Quadro 1); b) armazenamento da matriz (salvar); c) abertura do programa 'NetDraw'; d) importação da matriz salva em formato 'UCINET'; e) surgimento da rede; f] alteração de cores, tamanhos, formatos para melhor visualização dos autores citados; g) salvar arquivo como formato (.JPG).

\section{RESULTADOS E DISCUSSÃO}

Observou-se alguns aspectos relevantes a partir deste estudo, para discutir os resultados ora apresentados. Primeiramente se faz necessário compreender quais foram os 73 (setenta e três) autores mais representativos sobre as temáticas, ressaltando que quatro deles se repetem em mais temas e estão destacados (negrito).

Quadro 1: Autores que pesquisam sobre as temáticas.

\begin{tabular}{|c|c|c|c|}
\hline Autores & Tipos Documentais & Fluxos Informacionais & Avaliação de Documentos \\
\hline 1. ALBAGLI, S. & 0 & 2 & 0 \\
\hline 2. ALMEIDA, F. C. & 0 & 2 & 0 \\
\hline 3. ARANTES, A. A. & 0 & 0 & 2 \\
\hline 4. BARRETO, A. & 0 & 3 & 0 \\
\hline 5. BEAL, A. & 0 & 2 & 0 \\
\hline 6. BELLOTTO, H. L. & 7 & $\mathbf{0}$ & 2 \\
\hline 7. BERNARDES, I. P. & 0 & 0 & 5 \\
\hline 8. BLATTMANN, U. & 0 & 0 & 3 \\
\hline 9. BOSCHI, R. R. & 0 & 0 & 2 \\
\hline 10. CAMARGO, A. M. de A. & 3 & 0 & 0 \\
\hline 11. CARUCCI, P. & 3 & 0 & 0 \\
\hline 12. CASTELLS, M. & 0 & 3 & 0 \\
\hline 13. CASTRO, A. de M. e. & 0 & 0 & 4 \\
\hline 14. CASTRO, A. M. & 0 & 0 & 2 \\
\hline 15. CASTRO, A. M. G. de. & 0 & 2 & 0 \\
\hline 16. CONDE VILLAVERDE, M. L. & 2 & 0 & 0 \\
\hline 17. COOK, T. & 0 & 0 & 6 \\
\hline 18. COUTURE, $\mathrm{C}$. & 0 & 0 & 6 \\
\hline
\end{tabular}




\begin{tabular}{|c|c|c|c|}
\hline Autores & Tipos Documentais & Fluxos Informacionais & Avaliação de Documentos \\
\hline 19. DAVENPORT, T. & 0 & 4 & 0 \\
\hline 20. DELATORRE, H. & 0 & 0 & 2 \\
\hline 21. DOUGLAS, M. & 0 & 0 & 2 \\
\hline 22. DURANTI, L. & 4 & $\mathbf{0}$ & 2 \\
\hline 23. ESPOSEL, J. P. & 0 & 0 & 2 \\
\hline 24. FAUST, $\mathrm{K}$. & 0 & 2 & 0 \\
\hline 25. FONSECA, M. O. K. & 0 & 0 & 2 \\
\hline 26. FONSECA, V. M. M. da. & 0 & 0 & 2 \\
\hline 27. FOUCAULT, M. & 0 & 0 & 5 \\
\hline 28. GANANÇA, A. C. & 0 & 0 & 2 \\
\hline 29. GOHN, M. da G. & 0 & 0 & 2 \\
\hline 30. GOMES, Y. Q. & 0 & 0 & 2 \\
\hline 31. GONÇALVES, J. & 0 & 0 & 3 \\
\hline 32. GONZALEZ DE GOMEZ, M. N. & 0 & 0 & 2 \\
\hline 33. GOULART, $S$. & 2 & $\mathbf{0}$ & 2 \\
\hline 34. HEREDIA HERRERA, A. & 0 & 0 & 2 \\
\hline 35. HORTON, F.W. & 0 & 2 & 0 \\
\hline 36. INDOLFO, A. C. & 0 & 0 & 2 \\
\hline 37. JARDIM, J. M. & 0 & 0 & 10 \\
\hline 38. KIRK, J. & 0 & 2 & 0 \\
\hline 39. LE COADIC, Y. F. & 0 & 2 & 0 \\
\hline 40. LE GOFF, J. & 0 & 0 & 4 \\
\hline 41. LESCA, $\mathrm{H}$. & 2 & 2 & $\mathbf{0}$ \\
\hline 42. LODOLINI, E. & 0 & 0 & 3 \\
\hline 43. LOPES, L. C. & 0 & 0 & 3 \\
\hline 44. MACHADO, H. C. & 0 & 0 & 2 \\
\hline 45. MARQUES, A. A. da C. & 0 & 0 & 2 \\
\hline 46. MARTELETO, R. M. & 0 & 3 & 0 \\
\hline 47. MENESES, U. B. de. & 0 & 0 & 2 \\
\hline 48. MORAN, J. M. & 0 & 0 & 3 \\
\hline 49. NEGREIROS, L. R. & 0 & 0 & 2 \\
\hline 50. NONAKA, I. & 0 & 3 & 0 \\
\hline 51. NORA, P. & 0 & 0 & 2 \\
\hline 52. OLIVEIRA, A. R. de. & 0 & 0 & 2 \\
\hline 53. POLLAK, M. & 0 & 0 & 2 \\
\hline 54. PONJUÁN DANTE, G. & 0 & 3 & 0 \\
\hline 55. PORTER, M. E. & 0 & 2 & 0 \\
\hline 56. PRUSAK, L. & 0 & 4 & 0 \\
\hline 57. RHOADS, J. B. & 0 & 0 & 2 \\
\hline 58. RODRIGUES, A. C. & 2 & 0 & 0 \\
\hline 59. ROUSSEAU, J. Y. & 0 & 0 & 6 \\
\hline 60. SANTANA, M. A. & 0 & 0 & 2 \\
\hline 61. SANTOS, R. N. M. dos. & 0 & 3 & 0 \\
\hline 62. SCHELLENBERG, T. R. & 0 & 0 & 7 \\
\hline
\end{tabular}




\begin{tabular}{|l|c|c|c|}
\multicolumn{1}{|c|}{ Autores } & Tipos Documentais & Fluxos Informacionais & Avaliação de Documentos \\
\hline 63. SILVA, A. M. da & 0 & 0 & 3 \\
\hline 64. SOUSA, R. T. B. de. & 0 & 0 & 3 \\
\hline 65. TAKEUCHI H. & 0 & 3 & 0 \\
\hline 66. TARAPANOFF, K. & 0 & 2 & 0 \\
\hline 67. TOMAEL, M. I. & 0 & 3 & 0 \\
\hline 68. TRISTÃO, A. M. D. & 0 & 0 & 0 \\
\hline 69. VALENTIM, M. L. P. & 0 & 6 & 0 \\
\hline 70. VIEIRA, J. A. & 2 & 0 & 2 \\
\hline 71. WALCH, T. & 0 & 0 & 0 \\
\hline 72. WASSERMAN, S. & 0 & 2 & 0 \\
\hline 73. WURMAN, R. S. & 0 & 2 & \\
\hline
\end{tabular}

Fonte: Elaboração própria, 2016.

A partir da sistematização apresentada no Quadro 1, elaborou-se a Figura 1 aplicando-se o software 'UCINET', que apresenta a rede de autores representativos que estudam as referidas temáticas.

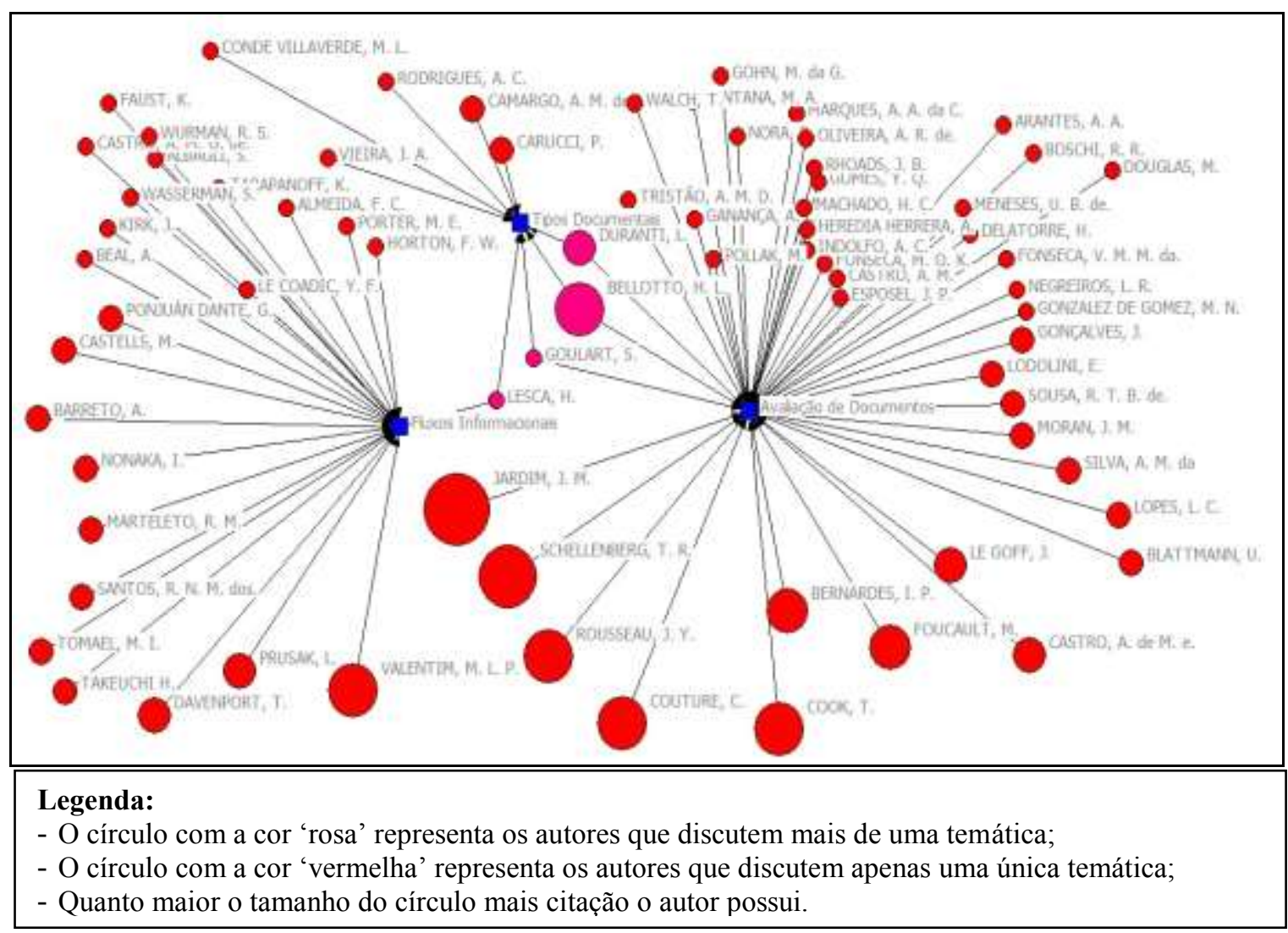

Figura 1: Rede de autores representativos que estudam as temáticas.

Fonte: Elaboração própria, 2016.

Destaca-se que apenas quatro dos autores trabalhados discutiram mais de um tema proposto: Lesca (tipos documentais e fluxos informacionais); Goulart (tipos documentais e avaliação de documentos); Bellotto (tipos documentais e avaliação de documentos); e Duranti (tipos documentais e avaliação de documentos), porém lendo os textos, observou-se que nenhum dos autores realiza a inter-relação entre os dois temas trabalhados. 
Os autores mais citados nos 'fluxos informacionais' foram Valentim com 6 trabalhos e Davenport e Prusak com 4 citações. Na temática relacionada aos 'tipos documentais' destaca-se Bellotto com 7 citações e Duranti com 4 citações. No que tange à última temática 'avaliação de documentos' destaca-se Jardim com 10 citações, Schellenberg em 7 e Cook, Couture e Rousseau com 6 citações. Assim, a partir deste estudo evidenciou-se que são os autores mais representativos da área.

Percebe-se que os autores das áreas de Ciência da Informação e de Arquivologia aqui pesquisados não evidenciaram em seus trabalhos a relação entre os temas centrais desta pesquisa, acredita-se que mesmo que em outros trabalhos algum autor estabeleça esta inter-relação, ainda assim, verifica-se que não há a clara compreensão do que de fato isso significa para as organizações empresariais.

\section{CONSIDERAÇÕES FINAIS}

Destaca-se no que tange os objetivos deste trabalho que realmente são poucos os autores que discutem de modo inter-relacionado as temáticas propostas por esta pesquisa, além disso, percebeu-se que há certo desconhecimento no que diz respeito a esta inter-relação e, por isso mesmo, há a necessidade deste estudo e de outros que relacionam esses elementos. Não obstante, o Subcomitê 11 do Comitê Técnico de Normalização (CTN) 46 da ISO, define no padrão ISO 15489-1:2016 a appraisal como um processo em que confluem esses objetivos e, atualmente, está em debate uma especificação técnica sobre este assunto, em que se inclui uma metodologia para sua abordagem.

No que se refere à inter-relação pouco debatida entre avaliação e fluxos de documentos/informações nos artigos pesquisados, atribui-se ao fato de que nos ambientes arquivísticos avaliam-se as séries (que são formadas de documentos e compreendidas como agrupações).

Identificar os tipos documentais, mapear os fluxos informacionais e avaliar documentos são atividades necessárias para que haja o gerenciamento e a recuperação de documentos, a fim de auxiliar no processo decisório em distintos tipos de atividades em ambientes organizacionais. Além disso, considera-se imprescindível assegurar - no que tange à continuidade digital nas organizações a memória organizacional, dado que devido a sua natureza binária, exige ativa desde o momento de sua produção.

Sendo assim, evidencia-se que discutir essas temáticas se constitui em algo relevante e inovador para a área, uma vez que são escassas as publicações que aprofundem a discussão da inter-relação desses fenômenos, e que no caso deste trabalho não se encontrou na literatura nenhuma inter-relação estabelecida.

\section{REFERÊNCIAS}

ARQUIVO NACIONAL (BRASIL). Conselho Nacional de Arquivos Classificação, temporalidade e destinação de documentos de arquivo: relativos às atividades-meio da administração pública/Arquivo Nacional. Rio de Janeiro: Arquivo Nacional, 2001.

INTERNATIONAL ORGANIZATION FOR STANDARDIZATION. ISO 15489-1: Information and Documentation. Records Management. Concepts and principles. Genebra, 2016.

ASOCIACIÓN Española de Normalización y Certificación. UNE-ISO 30301: 2011. Información y documentación. Sistemas de gesto para loas documentos. Requisitos. Madrid, AENOR, 2011. 
BELLOTTO, H. L. Arquivo: estudos e reflexões. Belo Horizonte: Editora UFMG, 2014.

Como fazer análise diplomática e análise tipológica de documento de arquivo.

São Paulo: Arquivo do Estado; Imprensa Oficial, 2002. 120p.

BERNARDES, I. P. Como avaliar documentos de arquivo. São Paulo: Arquivo do Estado, 1998.

CAMARGO, A. M. de A.; BELLOTTO, H. L. (Coord.). Dicionário de terminologia arquivística. São Paulo: AAB-SP/Secretaria de Estado de Cultura, 1996.

CASTELLS, M. 0 espaço de fluxos. In: A sociedade em rede. 6.ed. Rio de Janeiro: Paz e Terra, 2001. v.1; Cap.6: p.467-521

CERMEÑO MARTORELL, LL.; RIVAS PALÁ, E. Valorar y seleccionar documentos. Que y cómo se cace. Gijón: Trema, 2010.

CHIAVENATO, I. Introdução à teoria geral da administração: uma visão abrangente da moderna administração das organizações. 7.ed. Rio de Janeiro: Elsevier, 2003.

DELMAS, B. Manifeste polir une diplomatique Contemporânea: Des documentas institutionnels à l'information organizei. Paris: Gazeteei dez Aclives, 1996.

HEREDIA HERRERA, A. Linguajei y vocabulário archivísticos. Algo mau que uns diccionario. Sevilla: Junta de Anda lúcia; Concederia de Cultura, 2011.

HERNÁNDEZ OLIVERA, L.; MORO CABERO, M. Procedimento de valoración documental. Salamanca: ACAL, 2002.

MONTEIRO, N. A.; VALENTIM, M. L. P. Necessidades informacionais e aprendizagem no ciclo de vida de um projeto. Revista Digital de Biblioteconomia e Ciência da Informação, Campinas (SP), v.5, p.53-66, 2008.

NASCIMENTO, N. M. do. Tipos documentais e fluxos de informação como subsídios para o processo decisório em ambientes organizacionais. Marília: Unesp, 2014. 191f.

Dissertação (Mestrado) - Programa de Pós-Graduação em Ciência da Informação - Faculdade de Filosofia e Ciências (FFC) - Universidade Estadual Paulista (Unesp) - Campus de Marília.

PÉRES-MONTORO, M. Identificação y representação dele conocimiento organizacional: la propuseste epistemológica clásica. Barcelona: FUOC, 2004.

RODRIGUES, A. C. Diplomática contemporânea como fundamento metodológico da identificação de tipologia documental em arquivos. São Paulo: USP, 2008. 258f. Tese (Doutorado) - Programa de Pós-Graduação em História Social - Faculdade de Filosofia e Ciências Humanas - Universidade de São Paulo (USP).

SCHELLENBERG, T. R. Avaliação dos Documentos Públicos Modernos. In: Modernos: princípios e técnicas. Rio de Janeiro: FGV, 2006. Cap.12; p.179-230. . Arquivos

VALENTIM, M. L. P. Ambientes e fluxos de informação. In: (Org.). Ambientes e fluxos de informação. São Paulo: Polis; Cultura Acadêmica, 2010. Cap.1: p.13-22.

Gestão da informação e gestão do conhecimento em ambientes organizacionais: conceitos e compreensões. Tendências da Pesquisa Brasileira em Ciência da Informação, Brasília, v.1, n.1, p.1-16, 2008.

Equipes multidisciplinares na gestão da informação e conhecimento. In: BAPTISTA, S. G.; MUELLER, S. P. M. (Orós.). Profissional da informação: o espaço de trabalho. Brasília: Thesaurus, 2004. cap. 7: p.154-176. 
VILLARDEFRANCOS ÁLVAREZ, M. Del C. La identificação de fujo de información: una herramienta coligada para lagestión de información. In: CONGRESOINTERNACIONAL DE INFORMACIÓN (Info'2002), La Habana, Memória... Cuba: Biomundi: IDICT, 2002.

\section{NOTAS}

1 De acordo com a norma ISO 15489:1 (tradução nossa), a gestão de documentos, é a responsável pelo "controle eficaz e sistemático da criação, recepção, armazenamento, uso e a disposição de documentos de arquivo, incluindo os processos para capturar e manter a evidência e a informação sobre as atividades e operações da organização em forma de documentos".

2 A gestão da informação é um conjunto de estratégias que visa identificar as necessidades informacionais, mapear os fluxos formais de informação nos diferentes ambientes da organização, assim como sua coleta, filtragem, análise, organização, armazenagem e disseminação, objetivando apoiar o desenvolvimento das atividades cotidianas e a tomada de decisão no ambiente corporativo (VALENTIM, 2004, p.1).

${ }^{3}$ A gestão do conhecimento é um conjunto de atividades que visa trabalhar a cultura organizacional/informacional e a comunicação organizacional/informacional em ambientes organizacionais, no intuito de propiciar um ambiente positivo em relação à criação/geração, aquisição/apreensão, compartilhamento/socialização e uso/utilização de conhecimento, bem como mapear os fluxos informais (redes) existentes nesses espaços, com o objetivo de formalizá-los, na medida do possível, a fim de transformar o conhecimento gerado pelos indivíduos (tácito) em informação (explícito), de modo a subsidiar a geração de ideias, a solução de problemas e o processo decisório em âmbito organizacional (VALENTIM, 2008, p.4).

4 Modelo de Requisitos para Sistemas Informatizados de Gestão Arquivística de Documentos.

${ }^{5}$ Modelo de requisitos para a gestão de arquivos eletrônicos.

${ }^{6}$ Padrão de metadados do Governo Eletrônico.

APÊNDICE A - LISTA COMPLETA DE ARTIGOS ANALISADOS NA BRAPCI (JANEIRO/2016)

\section{FLUXOS INFORMACIONAIS}

1. ENNE, A. L. S. Conceito de rede e as sociedades contemporâneas. Comunicação \& Informação, v.7, n.2, jul./dez. 2004.

2. FROTA, M. G. da C.; QUINTAO, P. G. Fluxos informacionais para o monitoramento da Convenção dos Direitos da Criança: a atuação da rede NGO Grous for CRC. Encontros Bíblia: Revista Eletrônica de Biblioteconomia e Ciência da Informação, v.15, n.29, 1ํㅗ sem. 2010.

3. GREEF, A. C; FREITAS, M. do C. D. Fluxo enxuto de informação: um novo conceito. Perspectivas em Ciência da Informação, v.17, n.1, jane,/abr. 2012.

4. MACHADO, M.; BLATTMANN, U. A biblioteca universitária e sua relação com o projeto pedagógico de um curso de graduação. BIBLOS - Revista do Instituto de Ciências Humanas e da Informação, v.25, n.1, jan./jun. 2011.

5. MUSIÑO, C. M. Diagnóstico de Los fluxos de información e una empresa de consultoría em tecnologías de información. DataGramaZero, v.12, n.3, jun./2011.

6. PEREIRA, H. B. de B.; FREITAS, M. C.; SAMPAIO, R. R. Fluxos de informações e conhecimentos para inovações no arranjo produtivo local de confecções em Salvador, Bahia. DataGramaZero, v.8, n.4, ago. 2007.

7. PEREIRA, E. C. Metodologias para gestão da informação. Transinformação, v.15, n.3, set./dez. 2003.

8. SANTIN, D. M. Avanços e perspectivas da infometria e dos indicadores multidimensionais na análise de fluxos da informação e estruturas do conhecimento. Encontros Bibi: Revista Eletrônica de Biblioteconomia e Ciência da Informação, v.16, n.32, jul./dez. 2011. 
9. VALENTIM, M. L. P. Information flows and environments in business contexts: the meat sector case of Salamanca/Spain. Brasiliana Journal o Information Science, v.7, n. esp., 2013.

10. VALENTIM, M. L. P.; CARVALHO, E. L. de; WOIDA, L. M.; CASSIANO, E. L. Gestão da informação utilizando o método Infomapping. Perspectivas em Ciência da Informação, v.13, n.1, jan./abr. 2008.

11. VALENTIM, M. L. P. Gestão da informação e gestão do conhecimento em ambientes organizacionais. Tendências da Pesquisa Brasileira em Ciência da Informação, v.1, n.1, 2008.

12. VALENTIM, M. L. P. Inteligência competitiva em organizações: dado, informação e conhecimento. DataGramaZero, v.3, n.4, ago. 2002.

13. VERGUEIRO, W.; SUGAHARA, C. R. Aspectos conceituais e metodológicos de redes sociais e sua influência no estudo de fluxos de informação. Revista Digital de Biblioteconomia \& Ciência da Informação, v.7, n.2, jan./jun. 2010.

14. VITAL, L. P.; FLORIANI, V. M; VARVAKIS, G. Gerenciamento do fluxo de informação como suporte ao processo de tomada de decisão: revisão. Informação \& Informação, v.15, n.1, jan./jun. 2010.

\section{TIPOS DOCUMENTAIS}

1. CARVALHO, E. L. de; LONGO, R. M. J. Informação orgânica: recurso estratégico para tomada de decisão pelos membros do Conselho de Administração da UEL. Informação \& Informação, v.7, n.2, jul./dez. 2002.

2. SILVA, M. C. S. de M. e. Configuração da informação em documentos de ciência e tecnologia: estudo tipológico no arquivo pessoal do físico Bernhard Gross. Perspectivas em Ciência da Informação, v.18, n.3, 2013.

3. VALENTIM, M. L. P. Estrutura de bases de dados: modelos de metadados e a qualidade de resposta. Transinformação, v.13, n.1, jan./jun. 2001.

4. VIANA, C. M.; RODRIGUES, A. C. Identificação de Tipologia Documental como metodologia para organização de arquivos de Arquitetura. Tendências da Pesquisa Brasileira em Ciência da Informação, v.5, n.1, 2013.

\section{AVALIAÇÃO DE DOCUMENTOS}

1. INDOLFO, A. C. Gestão de Documentos: uma renovação epistemológica no universo da Arquivologia. Arquivística.net, v.3, n.2, jul./dez. 2007.

2. JARDIM, J. M. A invenção da memória nos arquivos públicos. Ciência da Informação, v.25, n.2, maio/ago. 1996.

3. LOUSADA, M. A evolução epistemológica do conceito de avaliação documental na arquivística e sua importância para a construção da memória. Revista Ibero-Americana de Ciência da Informação, v.5, n.2, 2012.

4. LOPES, L. C. A quadratura do círculo: a informação e algumas questões arquivísticas brasileiras. Ciência da Informação, v.23, n.3, set./dez. 1994.

5. MEDEIROS, N. L. de; AMARAL, C. G. A Representação do ciclo vital dos documentos: uma discussão sob a ótica da gestão de documentos. Em Questão: Revista da Faculdade de Biblioteconomia e Comunicação da UFRGS v.16, n.2, jul./dez. 2010.

6. MEDEIROS, N. L. de; NEGREIROS, L. R.; AMARAL, C. G. A experiência de arquivamento intermediário em escritórios de advocacia de Belo Horizonte, na ótica da gestão de documentos: estudo de casos múltiplos. Perspectivas em Ciência da Informação, v.16, n.2, 2011. 
7. OLIVEIRA, L. A. F. de; BORGES, J. A avaliação de documentos como requisito para a difusão do conhecimento em arquivos permanentes: estudos de caso nos arquivos histórico municipal de Salvador e público da Bahia. Ponto de Acesso, v.1, n.2, jul./dez. 2007.

8. PINTO, M. D. de S.; BLATTMANN, U.; KROEFF, M. S; TRISTÃO, A. M. D. Diversidade da recuperação de informações via internet na pesquisa e ensino. Revista ACB: Biblioteconomia em Santa Catarina, v.9, n.1, 2004

9. SILVA, E. P.; ORRICO, E. G. D. Associação de Arquivistas no Brasil na década de 1970. Revista Ibero-Americana de Ciência da Informação, v.5, n.2, 2012.

10. SCHÄFER, M. B.; LIMA, E. S. de. A classificação e a avaliação de documentos: análise de sua aplicação em um sistema de gestão de documentos arquivísticos digitais. Perspectivas em Ciência da Informação, v.17, n.3, 2012. 